\title{
UNIVERSITYOF
}

FORWARD

THINKING

WESTMINSTER用

WestminsterResearch

http://www.westminster.ac.uk/westminsterresearch

The Location of Cultural Authenticity: Identifying the Real and the

Fake in Urban Guizhou

Kendall, $\mathbf{P}$.

This is an author's accepted manuscript of an article to be published in the The China Journal, vol. 77, 2017. The final definitive version will be available online.

The WestminsterResearch online digital archive at the University of Westminster aims to make the research output of the University available to a wider audience. Copyright and Moral Rights remain with the authors and/or copyright owners.

Whilst further distribution of specific materials from within this archive is forbidden, you may freely distribute the URL of WestminsterResearch: ((http://westminsterresearch.wmin.ac.uk/)).

In case of abuse or copyright appearing without permission e-mail repository@westminster.ac.uk 


\title{
The Location of Cultural Authenticity: Identifying the Real and the Fake in Urban Guizhou
}

\section{Paul Kendall}

\begin{abstract}
This paper examines notions of cultural identity and authenticity, and how these notions are articulated in the small city of Kaili in Guizhou Province, an ethnically diverse region. Despite its urban status, Kaili has been branded by the local government as a yuanshengtai tourist destination. This Chinese term literally translates as "original ecology", but is used in ordinary conversation to denote a cultural authenticity in which people exist in quiet harmony with nature. Advertising uses the term to tout the ethnic cultural practices that mainly occur in the villages of Kaili's municipal periphery. In contrast, many local urban inhabitants - although amenable to the promotion of Kaili as a tourist destination - have rejected the notion that the city itself could be considered culturally authentic, and proudly declare themselves "fake" ethnic minorities, as against the "genuine" ethnic people of surrounding villages. These small-city inhabitants have also defined themselves against big-city visitors by attributing to the visitors a naïve fascination with cultural authenticity, while themselves remaining aloof from such practices. The cultural authenticity discourse in Kaili has thus facilitated a re-ordering of social and spatial hierarchies, as blasé small-city residents define themselves against both culturally authentic rural people and authenticity-seeking big-city tourists. In analyzing this, the paper draws out the broader implications regarding PRC notions of ethnicity, cultural practices, heritage, and identity.
\end{abstract}

One evening in 2011, in Kaili, a small city in Guizhou, I attended a provincial governmentorganized choral singing competition. A number of groups from Kaili and the surrounding counties of Qiandongnan Miao and Dong Autonomous Prefecture - of which Kaili is the capital - were competing for the right to progress to the provincial finals in Guiyang. ${ }^{1}$ It was mandatory for each administrative area of the prefecture to send a "representative group" (daibiao dui) to participate in

\footnotetext{
${ }^{1}$ This singing competition was a part of Colourful Guizhou (Duocai Guizhou), a long-running series of cultural events aimed at raising the profile of the province. For a short report on the Qiandongnan final, see Ouyang Bin, "2011 Duocai Guizhou gechang dasai Qiandongnan saiqu zongjuesai quanmian kaimu (Qiandongnan regional final of 2011 'Colourful Guizhou' singing competition begins)," in Qiandongnan Ribao (Qiandongnan Daily), June 15, 2011, 2.
} 
the competition. However, Tianzhu county had been either unable or unwilling to comply, and had subsequently paid a sum of money to a local Kaili choir - of which an acquaintance of mine, Xue Baojian, ${ }^{2}$ was a member - to covertly perform on their behalf. This unofficial proxy group performed the song The Miao Family Welcomes Happiness, adhering largely to Western choral music in terms of singing style, instrumental accompaniment and group structure, but with the addition of lyrical, melodic, and sartorial elements associated with the Miao minority. Unfortunately, the preceding group, from Jinping county, had performed exactly the same song. Consequently, the efforts of Tianzhu's unlikely representative group were received with amusement by the audience, and low marks by the judges.

After his performance, Xue Baojian spotted and joined me in the audience for the rest of the competition, during which time he passed frequent comment on the remaining acts. While around half of the groups adopted a performance style similar to his own group, there were also some acts which Baojian approvingly identified as "culturally authentic" (yuanshengtai $\square \square \square$ ). This assessment was in marked contrast to his amused references regarding the inauthenticity of his own group's performance. Beyond the fact that his Kaili-based group was clandestinely representing another county for money, he also pointed out that the "silver" ornamentation of their costumes consisted mainly of foil. At the same time, he was convinced of the authenticity of other performances in the same competition. He applied the label of yuanshengtai to a performance from Liping county, which the hosts presented as a "labor song" (laodong ge) of the Dong minority, and which began with performers imitating the sounds of farmyard animals. Baojian enthusiastically commented that the performers were "genuine peasants" (zhenzheng de nongmin), wider audience reaction was audibly positive, the television hostess declared that "the lives of working people are really happy", and the judges awarded their highest marks so far. A second Dong act, from Rongjiang county, trooped on stage and was declared yuanshengtai by Baojian even before singing had commenced. Just after his remark, the singers were joined on stage by a pianist and a conductor, prompting a swift reappraisal from Baojian; the Dong do not have this kind of thing in their music, he commented, and added, this group will definitely get a lower mark than Liping.

I encountered many similar references to yuanshengtai during nine months of fieldwork in Kaili city during 2011 and 2012. ${ }^{3}$ Since the mid-2000s, the term has operated in advertising to promote Kaili as a tourist destination for the experience of authentic minzu (or ethnic) culture rooted in a rural place. Monikers attached to Kaili, such as the "homeland of 100 festivals" and an

\footnotetext{
${ }^{2}$ Pseudonyms are used throughout this article.

${ }^{3}$ Fieldwork consisted of participant observations combined with 32 unstructured interviews and the reading of local newspapers, gazetteers, almanacs, tourism literature, and Party journals. I wish to express my gratitude to the University of Westminster, whose provision of a $\mathrm{PhD}$ scholarship made this fieldwork possible.
} 
"ocean of song and dance", ${ }^{4}$ have advertised the festivals of ethnic-minority groups who have long been associated with the most rural and remote parts of China. While this branding has conveyed a certain rural flavor, at the same time the local government has striven to transform Kaili into a bigger city. This focus on urbanism began during the mid-1990s and gathered pace during the early 2000s, with the instigation of a 'civilizing project' geared towards the facilitation of traffic, the development of urban infrastructure, the sanitization of streets, and official efforts to get the populace to act in a civil, orderly manner. This process has been aligned with the desire to create a clean and well-ordered tourist destination, but it has also created a dense urban environment at odds with the branding's emphasis on rural minzu practices.

While I have described elsewhere the branding strategy of Kaili as the homeland of 100 festivals despite its urban environment, ${ }^{5}$ in this article I ask how the inhabitants of Kaili experience and reinterpret their city in light of the obvious disparities between the city's branding and everyday urban life. Although amenable to the promotion of their city as a tourist destination, local inhabitants generally rejected the notion that Kaili could be considered culturally authentic, ${ }^{6}$ and instead reserved this term to describe surrounding villages. Some urbanites even conceived of Kaili as a city of "fake" ethnic minorities, in contrast to the "real" ethnic peasants of remote villages. In doing so, they undermined the minzu classification system of the PRC while simultaneously reinforcing the urban-centered othering of "genuine peasants". Their discourse involved more than a mere reiteration of the rural-urban divide; it enabled a reordering of urban hierarchies, as smallcity inhabitants patronized big-city visitors for their assumed fascination with exotic cultural practices. Yuanshengtai discourse thus both reinforced and complicated rural-urban hierarchies, as small-city residents defined themselves against both authenticated rural minorities and authenticityseeking big-city tourists.

\section{Yuanshengtai as Authenticity}

The literal translation of yuanshengtai as "original ecology" is clumsy but it highlights the fact that yuanshengtai suggests a strain of authenticity which stresses both the untainted original and

\footnotetext{
${ }^{4}$ For example, see "Kaili: zuoshou lüyou youshou yiju (Kaili: tourism on the one hand, liveability on the other)," Dangdai Guizhou (Guizhou Today), no. 9 (2010): 60.

${ }^{5}$ Paul Kendall, "Between Big City and Authentic Village: Branding the Small Chinese City," City 19, no. 5 (2015): 665-80.

6 To be precise, inhabitants invariably rejected the branding of Kaili as yuanshengtai during informal conversation, but when asked to describe the city during recorded interviews, it was relatively common for the same individuals to fall back on the stereotypical description of Kaili as yuanshengtai.
} 
humankind's relationship with the natural environment. ${ }^{7}$ It is a relatively new term for the description of cultural products, music and dance performances, having become a buzzword of the PRC media during the mid-2000s. It has also been employed by both Chinese and foreign scholars as a means to categorize, celebrate, and advocate the preservation of various cultural practices. ${ }^{8}$ While the majority of English-language works have focused on the usage of yuanshengtai in these media and academic contexts, ${ }^{9}$ this article follows this discourse into the everyday conversations of a small city. ${ }^{10}$

Outside of Chinese studies, there has been a good deal of literature in tourism studies relating to authenticity. ${ }^{11}$ In particular, Dean MacCannell, the trailblazer of tourism studies, has provided an interpretation of how authenticity was constructed under the specific conditions of Western modernity. ${ }^{12} \mathrm{He}$ argues that the Western tourist's quest for authenticity is motivated by the sense of inauthenticity produced by the fragmented and alienating experience of the modern everyday.

Tourists search for authenticity in sites that they consider both remote and pre-modern. However,

\footnotetext{
${ }^{7}$ The exact meaning of yuanshengtai has been contested. Scholars have generally agreed that it is an amalgamation of two words, the second of which, "shengtai", means "ecology". However, there has been less consensus over the first word, "yuan", which could be understood as "original", "primitive" or even "place". Fieldwork acquaintances commonly interpreted "yuan" as shorthand for "yuanshi", which can be translated as "original", "primeval", or "primitive", according to context. See Zhu Bingxiang, "Hewei 'Yuanshengtai'? Weihe 'Yuanshengtai?' (What Is Original Ecology and Why Original Ecology?)," Yuanshengtai Minzu Wenhua Xuekan (Journal of Original Ecological National Culture), no. 3 (2010): 1-4. ${ }^{8}$ For critiques of yuanshengtai, see Naran Bilik, “'Yuanshengtai' haishi 'huoshengtai'? (Original ecology or living ecology?)," Yuanshengtai Minzu Wenhua Xuekan (Journal of Original Ecological National Culture), no. 3 (2010): 14-7; Weng Naiqun, "Bei 'yuanshengtai' wenhua de renleixue sikao (Anthropological views on the influence of 'original ecology' culture)," Yuanshengtai Minzu Wenhua Xuekan (Journal of Original Ecological National Culture), no. 3 (2010): 5-13; and Zhu Fengyu, "Zhiyi: Yuanshengtai + Changfa? (Query: Yuanshengtai + Singing Technique?)," Renmin Yinyue (People's Music), no. 3 (2008): 31-33.

${ }^{9}$ For example, Lauren Gorfinkel, "From Transformation to Preservation: Music and Multi-Ethnic Unity on Television in China," in Music as Intangible Cultural Heritage: Policy, Ideology, and Practice in the Preservation of East Asian Traditions, ed. Keith Howard (Farnham: Ashgate, 2012), 99-112; and Helen Rees, "Environmental Crisis, Culture Loss, and a New Musical Aesthetic: China's 'Original Ecology Folksongs' In Theory and Practice," Ethnomusicology 60, no. 1 (2016): 53-88.

${ }^{10}$ In this context, "authentic" seems a more appropriate translation of yuanshengtai than "original
}

ecology"; the latter provides equivalence at word level, but does not reflect the casual, non-technical

language of the everyday in which yuanshengtai has become embedded.

${ }^{11}$ For example, Edward M. Bruner, "Abraham Lincoln as Authentic Reproduction: A Critique of Postmodernism," American Anthropologist, New Series, 96, no. 2 (1994): 397-415; Erik Cohen, "Authenticity and Commoditization in Tourism," Annals of Tourism Research 15, no. 3 (1988): 371-86; and Kjell Olsen, "Authenticity as a Concept in Tourism Research: The Social Organization of the Experience of Authenticity," Tourist Studies 2, no. 2 (2002): 159-82.

12 Dean MacCannell, "Staged Authenticity: Arrangements of Social Space in Tourist Settings," American Journal of Sociology 79, no. 3 (1973): 589-603; and Dean MacCannell, The Tourist: A New Theory of the Leisure Class (New York: Schocken Books, 1999 [1976]). 
this quest is doomed to failure; there can be no escape from the modern everyday, which pursues the tourist wherever he or she may travel. ${ }^{13}$

There are similarities between MacCannell's Western-oriented conceptualization of cultural authenticity and yuanshengtai, even though domestic tourism in southwest China has not developed in the same manner as mass Western tourism. Tourism as a commercial leisure activity was typically regarded as unacceptably bourgeois in Maoist China,,${ }^{14}$ and continued to be seen by some government officials as an immoral distraction from the task of production during the early post-Mao era. ${ }^{15}$ The recent explosion of tourism in southwest China over the last couple of decades is an extension of the triumph of Chinese consumerism, and at the same time has been entwined with the notion of heritage, which has also experienced a dramatic reversal in fortunes. Although heritage was not deliberately targeted for destruction during the 1980s - as it had been during the 1966 attack on the "Four Olds" - the recent domestic importance attached to heritage is predated by backpacker tourism in southwest China, which saw places such as Lijiang and Dali in Yunnan province become popular destinations for independent foreign tourists during the late 1980s and 1990s. China joined UNESCO's International Convention Concerning the Protection of World Cultural and Natural Heritage in 1985, but domestic heritage tourism did not really become properly established until the mid-1990s. ${ }^{16}$ Moreover, the intangible aspect of heritage tourism only became prominent in the mid-2000s, following China's ratification of the UNESCO Convention on the Safeguarding of the Intangible Cultural Heritage in 2004. ${ }^{17}$

Heritage is, of course, intertwined with notions of authenticity. The anthropologist Stevan Harrell has claimed an inherent tension in China's participation in the world heritage movement; it aspires to international standards as part of its nation-building efforts, yet these standards - with their stress on the authentic original - conflict with a Confucian tradition which does not clearly distinguish between the authentic and the new. ${ }^{18}$ According to Harrell, this tension has produced a tendency towards reconstruction and restoration in China, rather than preservation. ${ }^{19}$ Some scholars have also argued that Chinese tourists expect tourist sites to be developed and

\footnotetext{
${ }^{13}$ For a similar argument from the same era, see Henri Lefebvre, The Production of Space, trans. Donald Nicholson-Smith (Oxford: Blackwell, 1991 [1974]), 352-3.

${ }^{14}$ Socialism's own version of tourism consisted of visits to model villages such as Dazhai or Xiaojinzhuang.

15 Pál Nyíri, "Between Encouragement and Control: Tourism, Modernity and Discipline in China," in Asia on Tour: Exploring the Rise of Asian Tourism, ed. Tim Winter, Peggy Teo, and T. C. Chang (London: Routledge, 2009), 153-4.

${ }^{16}$ Xiaobo Su and Peggy Teo, The Politics of Heritage Tourism in China: A View from Lijiang (London $\square$ and New York: Routledge, 2009), 28.

${ }^{17}$ Harriet Evans and Michael Rowlands, "Reconceptualising Heritage in China: Museums, Development and Shifting Dynamics of Power," in Museums, Heritage and International Development, ed. Paul Basu and Wayne Modest (London: Routledge, 2015).

${ }^{18}$ Stevan Harrell, "China's Tangled Web of Heritage," in Cultural Heritage Politics in China, ed. Tami Blumenfield and Helaine Silverman (New York: Springer, 2013), 287-8.

${ }^{19}$ On the ideal of preservation through renewal and reconstruction in East and Southeast Asia, see also Anna Karlström, Preserving Impermanence: The Creation of Heritage in Vientiane, Laos (Uppsala: Uppsala University, 2009); and Evans and Rowlands, "Reconceptualising Heritage in China".
} 
performance-oriented, in contrast to authenticity-seeking Westerners. ${ }^{20}$ Yet these arguments either pre-date or overlook the Chinese discourse of yuanshengtai, which absolutely valorises the authentic original, even if the ideals of absolute cultural authenticity can never be realized. Many inhabitants of Kaili felt that both domestic and foreign tourists attached great value to authenticity, and as I argue below, conceptualized an authenticity of the original, rather than of a reconstructed authenticity. It therefore seems appropriate to understand yuanshengtai as belonging to a global discourse of cultural authenticity, which bears comparison with MacCannell's conceptualization of authenticity-seeking tourism as an attempt to escape the inauthentic modern everyday.

\section{Minzu and Rural Place in the "Cultural Authenticity" Discourse}

The China Central Television National Young Singer Competition is a well-known televised event which is briefly introduced here as an example of how yuanshengtai has operated nationally to denote authentic cultural practices rooted in rural ethnic locations. ${ }^{21}$ From 1986 until 2004, this event consisted of three singing categories: tongsu (pop), meisheng (bel canto), and minzu. In this context, minzu refers to a "national" style of professionalized folk singing, which often draws on minority-ethnic musical elements, but tends to stress technique rather than cultural authenticity. Since the early years of the Mao era - and before - musical development in China has been heavily influenced by the intertwined goals of modernization and nationalism, ${ }^{22}$ prompting the transformation of local genres, instruments and singing techniques into national forms. Minzu singing is one such national form, combining certain elements from Chinese folk opera and folksong with the techniques and training methods of Western music.

Organizers of the Young Singer Competition added a yuanshengtai singing category as a fourth category in 2006 in order to satisfy increased audience demand for authenticity, which could not be met by the professionalized minzu category. ${ }^{23}$ Whereas minzu singers were conservatoiretrained, yuanshengtai singers were to be amateurs who had been raised in an environment permeated with orally-transmitted, unamplified music. Whereas minzu singers performed in standard Mandarin, yuanshengtai singers were to sing in their original dialect or ethnic-minority

\footnotetext{
${ }^{20}$ See Tim Oakes, Tourism and Modernity in China (London: Routledge, 1998), 2; Tim Oakes, "The Village as Theme Park: Mimesis and Authenticity in Chinese Tourism," in Translocal China: Linkages, Identities and the Reimagining of Space, ed. Tim Oakes and Louisa Schein (New York, NY: Routledge, 2005), 183-4; and Nyíri, "Between Encouragement and Control", 156.

${ }^{21}$ For more extensive analyses of the Young Singer Competition, see Yang Mang, "The Yuanshengtai Movement: Remaking of Chinese Ethnic Minority Identity" (MA thesis, University of Hawai'i, 2009); Lauren Gorfinkel, "From Transformation to Preservation"; and Rowan Pease, "Broken Voices".

22 Scholars have already comprehensively examined the values which have informed efforts at musical modernization by state-funded conservatories, composers and ensembles, as well as their musical results. For example, see Richard Curt Kraus, Pianos and Politics in China: Middle-Class Ambitions and the Struggle Over Western Music (New York: Oxford University Press, 1989); Jonathan Stock, Musical Creativity in Twentieth-Century China: Abing, His Music, and Its Changing Meanings, (Rochester: University of Rochester Press, 1996); and Andrew Jones, Yellow Music: Media Culture and Colonial Modernity in the Chinese Jazz Age (Durham: Duke University Press, 2001).

${ }^{23}$ Rowan Pease, "Broken Voices," 195.
} 
language. In contrast to both the minzu and bel canto styles, with their strict, standardized technical demands, the yuanshengtai category lacked consistency of technique, with singers potentially performing in any folk style from one of China's 27 provinces and autonomous regions. Instead of technique, it was the assumed cultural and ecological origins of yuanshengtai entries which gave coherence to this singing category. A yuanshengtai entry - in its ideal form ${ }^{24}$ - was an authentic rendition of everyday amateur practices which had emerged in a location defined by harmonious relations between humankind and the natural environment.

This underlying conceptualization of place was present not just in the Young Singer Competition but also in the comments of my acquaintances in Kaili city. One of my interviewees a student at Kaili University - stressed the lack of electricity in yuanshengtai locales, which meant that "everything is done using what is given by the natural world". Another interviewee, a young worker in the prefectural branch of the commerce bureau, added timelessness to this notion of naturalness, explaining that yuanshengtai is "a really natural thing, it is what it is; over a millennium, a century, a decade, it has maintained the same appearance, and it hasn't changed". A third interviewee, a young university teacher, described yuanshengtai as something which has "not been affected too much by outside culture".

Given this underlying conceptualization of place, it is not surprising that yuanshengtai has often been associated with ethnic minorities, particularly of the southwest, since these groups have themselves long been associated with the rural, the natural, and the pre-modern. Thus, in the Young Singer Competition, ethnic-minority performers predominated in the yuanshengtai category, not rural Han. ${ }^{25}$ Louisa Schein has argued that cosmopolitan Han Chinese began to look to rural ethnicinority cultures as "reservoirs of still-extant authenticity" during the cultural identity crisis of the 1980s, following the destructive years of the Cultural Revolution and the imported foreign cultural products of the early reform years. ${ }^{26}$ In the early twenty-first century, the discourse of yuanshengtai has been a continuation of this search for authenticity in rural minzu locales. This search has also been accelerated by a shift towards the intertwined political strategies of urbanism and consumerism. In the realm of consumption, the ability to differentiate between the authentic original and the counterfeit has become a potential matter of life and death as a consequence of shanzhai (knock-off) culture. XX This innovative strain of commercialism has involved the sale of not only fake clothing brands but also fake (and sometimes toxic) milk powder and even fake eggs. Thus, in her study of Dali in Yunnan, anthropologist Beth Notar has argued that authenticity is a matter of concern not only for Western travellers but also local inhabitants. Increased commodification has contributed to "authenticity anxiety" among Dali townspeople, who in their

\footnotetext{
${ }^{24}$ It should be stressed that yuanshengtai did not always appear in this ideal form; Qinghai Television's entry to the 2010 Young Singer Competition included two performers dancing in a two-piece yak costume.

${ }^{25}$ Yang Man, "The Yuanshengtai Movement", 55.

${ }^{26}$ Louisa Schein, "Gender and Internal Orientalism in China," Modern China 23, no. 1 (1997): 71-2.
} 
role as consumers have become increasingly concerned about the circulation of fake products and fake money (i.e., counterfeit notes).$^{27}$

Rapid urbanization has rendered rural authenticity increasingly precious at the same time as the urban has extended into the rural through the development of infrastructure to facilitate city tourists' consumption of publicized authenticity. An increase in leisure time and mobility, as well as improved transport, has meant that predominantly rural areas such as southeast Guizhou are easily accessible for urban tourists. Yet this is just one aspect of a dual process, as described by anthropologist Jenny Chio, whereby the rural is brought closer to modern China through infrastructural development but simultaneously characterized as distant in order to serve as an attractive destination for domestic tourism. ${ }^{28}$ Under such conditions, the rural, more than ever, becomes the nurturer of traditions which are threatened by urbanization and modernization.

Although an urban authenticity is possible,${ }^{29}$ the city is no place for the fragile, orally-transmitted culture of yuanshengtai. The spread of the urban fabric - in terms of both tourism and infrastructure - threatens the existence of what could be considered yuanshengtai, but it is this same threat which makes yuanshengtai valuable and accessible. This is a contradiction with which the branding of Kaili has grappled - in order to promote Kaili as both an accessible, developed tourist destination and the homeland of 100 festivals - and it is also one that has shaped discourses of authenticity in the everyday life of the city.

\section{Locating Authenticity}

The spatial location - rather than the artistic content - of yuanshengtai has been a matter of ambivalence in the branding of Kaili as a tourist destination. Yet in everyday conversations in Kaili, the location of a cultural practice was often the decisive factor in determining whether or not local inhabitants described it as yuanshengtai. Indeed, fieldwork participants even used the term to denote rural places, as well as the cultural practices which these places nurtured. In contrast, they declared that the city of Kaili did not possess cultural authenticity on account of its modernization and urbanization.

I had first met Xue Baojian at a choir practice in a Kaili park. Both he and the other choir singers never accepted that I could have travelled so far to study music in an urban setting, and they made repeated efforts to send me to the countryside in order to experience authentic ethnicminority music. During one conversation, Auntie Zhang, a retired Qiandongnan Daily clerk, insisted that I must go and hear Dong Big Songs at a village in Congjiang county, known as a birthplace of this musical genre. Her friend, Auntie Yang, countered that this village was not the

\footnotetext{
${ }^{27}$ Beth E. Notar, "Authenticity Anxiety and Counterfeit Confidence: Outsourcing Souvenirs, Changing Money, and Narrating Value in Reform-Era China," Modern China 32, no. 1 (2006): 64-70.

${ }^{28}$ Jenny Chio, “The Appearance of the Rural in China's Tourism," Provincial China 3, no. 1 (2011): 60-78.

${ }^{29}$ As a specifically rural form of authenticity, yuanshengtai does not encompass the urban authenticity found in other city brands, such as "old Beijing" culture or former colonial architecture.
} 
only place for Dong Big Songs; I could also hear them in the villages of Liping county, although not the county town of Liping itself. I responded that I had already heard Dong Big Songs at Kaili University. The two friends were united in their assertion that anything sung at Kaili University could not be considered genuine yuanshengtai.

This assertion of inauthenticity was not entirely based upon considerations of location. National media, academic articles and everyday conversations in Kaili have additionally conceptualized yuanshengtai as self-organized amateur activity which occurs as a natural expression of everyday life, whether for the sake of self- entertainment or traditional societal functions such as ritual and courting. In contrast, the musical activity promoted as yuanshengtai in Kaili usually constituted professionalized entertainment for others. The music department at Kaili University ran a "class for the transmitters of minzu culture", which consisted of training students for potential careers in the performance of yuanshengtai music. Funded by the provincial government, this five-year vocational degree (zhuanke) offered subsidized classes to high-school graduates who ostensibly came from impoverished rural families, but whose numbers also included under-achievers from mainstream urban education. First-year students had to study not only the representative musical genres of the Dong and Miao minorities, but also more generic skills such as bel canto, music theory, and piano; that is, the kind of professional and "scientific" training against which yuanshengtai is commonly defined. This kind of training extended into the yuanshengtai classes. Rather than learn the six-pipe lusheng, an instrument commonly seen in the festivals of Kaili municipality's rural periphery, students learned to play a modernized lusheng, usually a 19pipe version, which facilitated displays of professional virtuosity.

While the formal practices of university departments and song-and-dance troupes may be far removed from the amateur ideals of yuanshengtai, there is a great deal of amateur music for selfentertainment in Kaili city, particularly among the elderly. Indeed, the term "self-entertainment" (ziyu zile) was often employed by Kaili inhabitants to describe their own everyday artistic practices. In terms of musicianship and social functions, these urban activities were closer to the amateur ideals of yuanshengtai than the professionalized performances of local song-and-dance troupes. Yet to make this comparison would be to ignore notions of space, minzu, and ultimately, hierarchy, which meant that I never encountered an instance where urban amateur activity was described as yuanshengtai during my fieldwork in Kaili. Ultimately, rural location was the most important determinant of yuanshengtai cultural authenticity, to the extent that amateurism and even musical sound were relegated to secondary considerations, as indicated by the following vignette.

During my first fieldwork visit to Kaili, Lan Xunyi, a conservatoire-trained Dong singer, insisted on taking me to Xijiang, a well-known Miao settlement in Leishan county. Travelling by car, we arrived in the early evening, just in time to catch the second half of a daily scheduled performance. I was particularly struck by one song, There Is a Place Called Xijiang (You ge difang jiao Xijiang), performed by a male singer in standard Chinese, with a vocal technique closer to bel 
canto than Miao folksong. The singer was accompanied by a backing track of lusheng, synthesizers and strings. Xunyi seemed surprised when I queried the genre to which the performance belonged, saying she thought it was "very yuanshengtai". A few days later, I observed another performance in one of Kaili city's two main song-and-dance restaurants, whose offerings appeared far closer to the musical ideals of yuanshengtai, with genuine acoustic Dong instruments and a less blatantly conservatoire-trained singing style. However, Xunyi had previously dismissed music in this and the other song-and-dance restaurants of Kaili as too "performance-style" (biaoyanxing) and not indigenous to the city. She also told me that people tended not to visit those places any more because of the trend towards yuanshengtai, and preferred to go to the villages instead.

While the majority of my Kaili acquaintances agreed that there was no yuanshengtai in the city, there were divergences of opinion as to exactly which rural areas of Qiandongnan possessed and constituted - yuanshengtai. Those with stricter criteria than Xunyi declared that there was little about Xijiang that could be considered yuanshengtai. A retiree scoffed when I mentioned Xijiang during a conversation about yuanshengtai, dismissing it as "man-made" (renmin zao de). All human settlements are, of course, man-made, but his reaction implied that there was something especially artificial about contemporary Xijiang. During another debate among the park's choir singers, Auntie Yang argued that Xijiang had become "commercialized" (shangyehua); the locals did not even grow their vegetables in Xijiang any more, but rather purchased them from stores in the city. According to the choir's chief erhu player, Xijiang had been genuinely minzu during the 1990s, prior to its development (kaifa).

As indicated by these comments, both development and commercialization were frequently presented as destroying the authenticity of not only everyday cultural practices but also a rural minority place itself. For those with strict criteria, Xijiang's stage performances were the cultural expression of a tourist destination rather than of a rural minority place. In contrast, there was almost unanimous praise for the more remote village of Basha in Congjiang county as a place of exotic cultural practices. Whereas the urban fabric had already permeated Xijiang through tourism and infrastructural development, Basha was still yuanshengtai, at least for the time being. As a general rule, the further away a village or region was situated from Kaili, the greater the likelihood of consensus among urban inhabitants that it was yuanshengtai. Auntie Yang therefore dismissed as inauthentic those annual festivals which took place in villages within the administrative boundaries of Kaili municipality, despite featuring six-pipe lusheng and many amateur performers. With location as the main authenticator, other properties of yuanshengtai, such as amateurism, spontaneity, minzu flavor, and self-organization, derived from its existence in a remote, rural place.

\section{Identifying the Real and the Fake}

The importance of location was such that even the presence of ethnic people did not guarantee the existence of yuanshengtai. None of my fieldwork acquaintances denied the presence of a 
substantial non-Han population in Kaili city, and some even over-estimated the percentage of mithe ethnic-minority populace in the city in comparison to official statistics. ${ }^{30}$ However, everyday discourse identified two types of ethnic people - real and fake - and only the real minority-ethic people were associated with yuanshengtai. In contrast, the fake ethnic populace was the product of an urban and modern lifestyle, and no longer spoke the language or practiced the customs of their official minzu category. The city produced fake minorities, just as rural place produced real minorities and yuanshengtai.

In order to be a real minority, a person had to have been born and raised in a rural place, since only continuous dwelling in a rural environment enabled the continued practice of an ethnic language and customs. During another conversation in the park, Auntie Zhang had been making some sweeping statements about Miao festivals, and I had pointedly asked if she was Miao herself. No, I'm Han, she replied. In fact, she continued, I do not think there are any real Miao (zhenzheng de Miao) here in our group, only fake Miao (jia Miao). At which point, Auntie Yang, something of a contrarian, interrupted to assert that she was in fact a real Dong. So what makes somebody a fake Miao, I asked? They cannot speak the ethnic language (yuyan butong), and are not born-and-bred in the location in which they reside, answered Auntie Yang.

According to her criteria, only a small percentage of the city's population could be considered real ethnic people, given the many waves of new arrivals to Kaili during the PRC era, as well the linguistic dominance of standard Chinese and its Kaili variant. Instead of being the home to "real" minorities, inhabitants described Kaili as a new city, even as an "immigrant city" (yimin chengshi), where various cultures had intermingled with each other. Such descriptions were apt considering the recent history of Kaili, which has seen a constant influx of newcomers, arriving first with the administrative headquarters of Qiandongnan in the 1950s, then with the Third Front shift of industry to inland regions in the $1960 \mathrm{~s},{ }^{31}$ and finally with the development of tourism in the postMao era.

When urban residents referred to themselves as fake Dong or fake Miao, and as sinicized (hanhua), I initially assumed this to be a negative self-description. However, I eventually realized that urban ethnic minorities could be proud of their self-proclaimed fake minzu status. This came to my attention during an interview with another student at Kaili University.

\footnotetext{
${ }^{30}$ According to these statistics, the Miao have always been numerically dominant in Kaili municipality, and constituted $66.98 \%$ of the population in 2013 . However, if only the urban districts of Kaili are considered, the Han already had a narrow majority by the time of the 2000 census, at $43 \%$ of the population, compared to 39.5\% Miao and 11\% Dong. See Liu Daichun, ed., Guizhou Sheng 2000 Nian Renkou Pucha Ziliao: Shang $\mathrm{Ce}$ (Tabulation on the 2000 Population Census of Guizhou Province: Volume One) (Beijing: Zhongguo tongji chubanshe, 2002), 16-17; and Liang Guigang, ed., Guizhou Sheng Nianjian 2013 (Guizhou Yearbook 2013) (Guiyang: Guizhou nianjian she chuban, 2013), 515.

31 The hugely ambitious and expensive Third Front project came to Kaili in the form of 10 central-run industrial enterprises (zhongyang changkuang). These work units and their workers were relocated to Kaili from Beijing, Tianjin and other more industrially-developed cities.
} 
A: Although I'm an ethnic-minority person, I'm fake (laughs).

Me: In what way fake?

A: I've already been sinicized (yijing bei hanhua le). My own minority [the Buyi] have their own language, but I can't [speak it]. ... Nowadays, it's a diverse society, it's not like, you're in a minority area, so I expect you to sing Miao songs, speak Miao, and do everything in this way. It can't be like this, society is already open to the outside world.

Me: So "fake Miao" is not necessarily a negative word, then?

A: No, it's not negative, it's not negative. It's just to say that an individual hasn't carried forward Miao culture, hasn't carried forward the culture of their minzu, that they already have a Han-style and relatively modern lifestyle ...it's not negative (laughs), it's not negative.

The fake could sometimes be better than the authentic original; there was a discernible pride among many urbanities who self-identified as "fake Miao" or "fake Dong". This celebration of the fake appeared to conflict with the seeming adulation of the authentic by Kaili inhabitants that I encountered during my time in the city. However, there were good reasons to be a fake minority. Most obvious were those cases where a person was born of a mixed minzu (minority and Han) relationship. In such cases, parents might choose ethnic-minority status for their child in order that he or she could enjoy state privileges, particularly bonus points for the all-important university entrance examination (gaokao). For example, one interviewee, a high school student, asserted that he was Han, but his Dong mother had changed his minzu status to her own in order for him to gain an extra twenty points for the high school entrance examination; "one point is worth 10,000RMB [in future earnings]", he quipped.

However, the official perks of ethnic status cannot explain why some individuals from pure ethnic-minority families also described themselves as fake minzu. As a Miao high-school student explained to me, her family was originally from a village in Kaili municipality, but she was a fake Miao because she had grown up in the city. Although such comments were most common among young urbanites, elderly acquaintances also made similar statements. For example, the aforementioned choir's erhu player was amused when I asked him about his plans for the Miao New Year; no, we're not Miao, we're already sinicized, he said, before adding that he felt this applied to Kaili city as a whole.

It was therefore the modern city environment, rather than simply lineage, which produced fake minorities. Identification with the sinicized and the fake derived from self-association with the modern and the urban in a heavily weighted discursive environment, as against the authentic but backward ethnic-minority populace of surrounding villages. Beneath its superficially positive celebration of authenticity, yuanshengtai carried a negative layer of association with economic backwardness, and some of Kaili's inhabitants were well aware of this association. Some reacted against the yuanshengtai label, such as a hip-hop dancer and studio owner: 
My personal viewpoint is one of antipathy towards this word, because wherever you go [outside of Kaili], people say "yuanshengtai, yuanshengtai". Actually, I think this city is really diverse. The government is doing its high-intensity city propaganda, and it always does yuanshengtai. Actually, yuanshengtai, speaking about it in a nice-sounding way, it's our special local minzu characteristics, but speaking in a less nice way, it means "primitive". So when people say "oh, you there [in that place], you're really yuanshengtai", it sounds like a positive term, but it's actually derogatory.

Those who label others yuanshengtai may appear to be paying a compliment, but they are also asserting their superiority in the context of China's socio-spatial hierarchies, where to be sinicized and urban is to be modern while to be ethnic-minority and rural is to be backward. Naran Bilik and Weng Naiqun have both argued that rural dwellers do not choose the tag of yuanshengtai, but are instead "authenticated" (bei yuanshengtai) by urbanites nostalgic for a pre-modern lifestyle. ${ }^{32}$ Uniquely, the urban ethnic-minority populace of Kaili straddle this binary: they speak Mandarin, but have official minority status; they live in Qiandongnan, an area associated with yuanshengtai, but within a city. They could choose to identify with either yuanshengtai culture or urban society. Many such young people who were officially designated as being ethnic-minority, in particular, embraced the urban, as fake minorities, and rejected yuanshengtai.

Studies of authenticity and minzu in other parts of China have yielded findings which bear some comparison with the fake minorities of Kaili. Anthropologist Beth Notar has argued that speakers of the Bai minority language in Dali, Yunnan, associate the false with Han Chinese and external things, and the real with the local Bai. ${ }^{33}$ Anthropologist Joanne Smith Finley has written of how in Xinjiang, Uyghurs educated in the Uyghur language (minkaomin) have come to regard Uyghurs educated in Chinese (minkaohan) as almost a separate ethnic group, while the minkaohan themselves oscillate between feelings of shame at cultural loss and pride in their identification with the modern. ${ }^{34}$ However, fake minorities in Kaili were far less ambiguous in their identification with the modern city, to the extent that they openly celebrated their fakeness in opposition to the "real" minorities of yuanshengtai. This discourse of real and fake partially reinforced notions of bounded minzu categories by heralding the practice of certain cultural forms as evidence of ethnic status. Yet at the same time, it facilitated the escape from these categories and their negative associations; since the urbanities of Kaili did not themselves engage in yuanshengtai practices or speak minority languages, they could claim sinicization, even in opposition to their own official ethnic status or

\footnotetext{
${ }^{32}$ Naran Bilik, “'Yuanshengtai' haishi 'huoshengtai'?”; Weng Naiqun, "Bei 'yuanshengtai' wenhua”.

${ }^{33}$ Beth E. Notar, "Authenticity Anxiety," 69.

${ }^{34}$ Joanne Smith Finley, "'Ethnic Anomaly' or Modern Uyghur Survivor" A Case Study of the Minkaohan Hybrid Identity of Xinjiang," in Situating the Uyghurs between China and Central Asia, ed. Ildikó BellérHann et al. (Aldershot, England: Ashgate, 2007), 219-37.
} 
familial background. If there are multiple ways of being ethnic in southwest China, then the minorities of Kaili indicated that there are also ways of not being ethnic, as they stressed their contemporary urban circumstances in order to gain membership to the "unmarked category" of the Han majority. ${ }^{35}$

\section{Repositioning the Small City}

Although urban Kaili produces fake ethnic-minority pepole and rural Qiandongnan produces yuanshengtai, the rural-urban divide was not the only geographical imagination relevant to the local discourse of authenticity. Instead, the rural-urban divide appeared to exist alongside a more complex conceptualization of village, small city and big city, which separated Kaili from big cities - domestic or otherwise - and even elevated it above them. An interviewee referred to the government and city as "doing yuanshengtai" and a music student at Kaili University described Kaili as a "gathering point" (jujidi) for yuanshengtai; despite not possessing real yuanshengtai, the city enabled the assembly and concentration of cultural practices from the surrounding counties. Kaili was thus positioned as an intermediary between the village and the big city, as a small city which packaged and produced yuanshengtai from the supposed raw materials of rural culture for consumers from Beijing, Shanghai, and beyond.

An interview with a third Kaili University student hinted that the yuanshengtai discourse involves more than just the two oppositional elements of urban and rural. This student had been raised in Kaili, but has many relatives who continued to work as farmers in remote parts of Qiandongnan. He did not consider Kaili to be yuanshengtai, but felt that tourists saw things differently:

Tourists think Kaili's air is good, and it's the most basic kind of lifestyle, without the pursuit of things, so they think that it's a yuanshengtai lifestyle. Not exactly that it's primitive, but that it's a relatively simple lifestyle.... If you're talking about Beijingers, then Kaili can be considered yuanshengtai. But as far as Kaili people are concerned, the life of people out in the countryside, in the counties, is yuanshengtai, where they're tilling the land and planting in the fields....

For this student, yuanshengtai is a "relative thing", whose location depends on the residential location of the person making the classification. However, there was a further difference between Beijingers - as understood by the interviewee - and many of Kaili's inhabitants, in that the latter sang the praises of rural yuanshengtai without themselves being consumers. I initially missed this

\footnotetext{
${ }^{35}$ Stevan Harrell, Ways of Being Ethnic in Southwest China (Seattle: University of Washington Press, 2001); Dru C. Gladney, "Representing Nationality in China: Refiguring Majority/Minority Identities," The Journal of Asian Studies 53, no. 1 (1994): 118.
} 
last point, that many fieldwork acquaintances themselves had no personal interest in hearing and seeing yuanshengtai. They had frequently recommended that I visit remote villages in order to experience yuanshengtai, and I had assumed that an individual would only recommend something that he or she also personally enjoyed. A twenty-something Kaili friend once told me that he appreciated that foreigners were interested in yuanshengtai but locals like him were already really bored with it. I slowly came to realize that this lack of interest was shared by many other acquaintances, including those who had enthusiastically recommended that I explore yuanshengtai.

This became particularly obvious during festive periods, when there were many opportunities to observe rural cultural practices, particularly lusheng-dancing and bull-fighting. During the first lunar month of 2012, I followed a festival circuit around Kaili's rural perhiphery, attending events in multiple villages, as well as Kaili city proper. I talked with a local tax officer and his friends about my festival trip; and he responded, "yeah, it's interesting when you first go." "But when we go," added his friend, "it's just people watching people" (ren kan ren). A 20-something urban Miao responded when I asked if she had any plans for the Miao New Year, "Haven't you noticed yet, we locals in Kaili aren't interested in that stuff, it happened a long time ago here." Nor were such responses restricted to younger people. I talked about festivals with middle-aged and elderly members of an indoor choir which I frequently attended. "I'm already used to seeing the festivals, and don't want to see them anymore," laughed one female singer, who was officially Dong but claimed sinicization.

International and domestic tourists might think of Qiandongnan as a "strange" (xiqi) land, but the local customs no longer held any great fascination for many Kaili residents, especially those who were officially minorities and had been raised in the area. They had heard and seen it all before. Beyond distancing fake minorities from their rural cousins, the blasé attitude of Kaili urbanites towards yuanshengtai also reconfigured the hierarchy between small and big city. Kaili has admittedly relied quite heavily on the visits and proclamations of cosmopolitan researchers, preservationists and cultural commentators for the promotion of local tourism. However, locals were to an extent humouring visitors such as myself when they waxed lyrical about yuanshengtai, as something which might impress inexperienced outsiders, but in which they had no personal interest. While the surrounding remote villages were the true locations of yuanshengtai, Kaili was the disinterested packager of yuanshengtai for visitors from other cities. It was these visitors who were the genuine consumers of yuanshengtai, while those who dwelt in the packaging zone were close enough to the product to understand it, but not so close that they had become part of the product.

Throughout this paper, I have stressed the spatial aspects of yuanshengtai discourse. At the heart of yuanshengtai is a conceptualization of rural place as a nurturer of authentic cultural practices and genuine minorities. Whereas studio-based performances of yuanshengtai are merely 
representations of this rural place, Kaili is a purported homeland of yuanshengtai. Local branding has accordingly attempted to present the Kaili itself as yuanshengtai, despite recent modernization and urbanization. While understandably willing to support the promotion of their city, the inhabitants of Kaili have firmly located yuanshengtai outside of the city, in the surrounding rural hinterland. In the process, Kaili has become the homeland of the self-proclaimed fake minority, who enthusiastically recommend yuanshengtai to visitors from the big cities while remaining personally aloof from such rural practices. This entails a representation of big-city tourists as authenticity-seekers which is certainly debatable, but which accords with the wider assumption of place and heritage promotion that it is the timeless and the rural which most deserves to be valorized as representative of ethnic practices. And it is this same assumption which has produced a desire among urbanities in Kaili - and perhaps the inhabitants of other southwest tourist cities to delink themselves from marked ethnic practices and categories. For such individuals, it is preferable to position themselves as unmarked subjects within the modernizing discourse of the urban - and even to reconfigure urban hierarchies of small and big city - rather than to serve as the backward ethnic tourees against whom the modern tourist is defined. 